\title{
Stagnating maternal mortality in Tanzania: what went wrong and what can be done
}

RUMISHAEL S. SHOO ${ }^{*}$, LEONARD E.G. MBOERA² SYDNEY NDEKI ${ }^{1}$ and GASPAR MUNISHI ${ }^{1}$

'PRAXIS for Social Service Systems, P.O. Box 25594, Dar es Salaam, Tanzania

${ }^{2}$ National Institute of Medical Research, P.O. Box 9653, Dar es Salaam, Tanzania

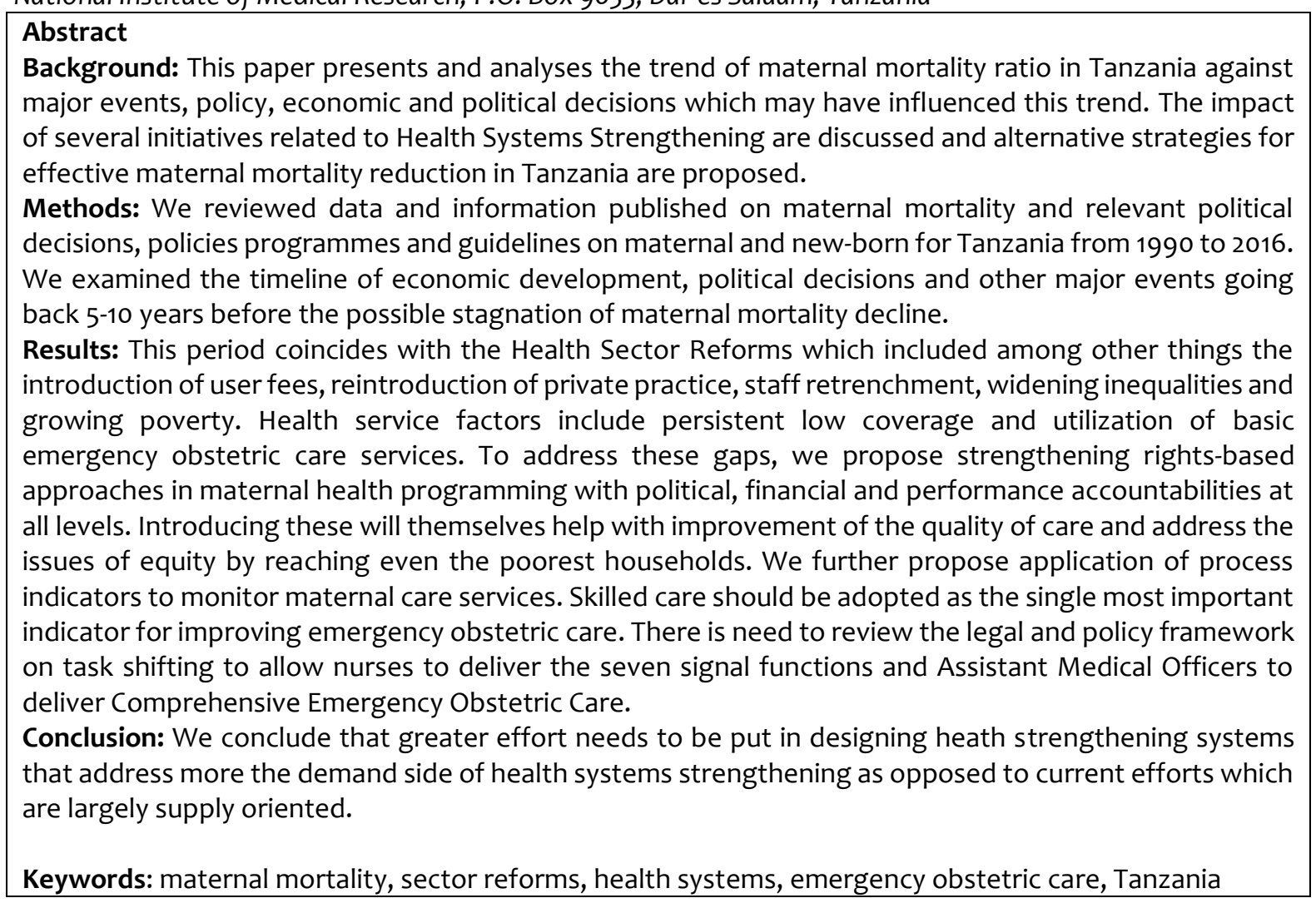

\section{Introduction}

The Sustainable Development Goal (SDG) Number 3 seeks to ensure health and well-being for all, at every stage of life (https://unstats.un.org/sdgs/report/2016/). The goal addresses all major health priorities including maternal and child health. Maternal mortality is an indicator used to asssess the access and quality of maternal care. Substantial global reduction of maternal mortality was achieved globally between 1990 and 2015 with a drop of 43\% from 385 to 216/100,000 (Alkema et al., 2016; GBD, 2016). The SDG global target is to reduce the global maternal mortality ratio (MMR) to less than 70 per 100,000 live births by 2030 (https://unstats.un.org/sdgs/report/2016/). However, individual countries are required to set their national target - that by 2030 , every country should reduce its MMR by at least two-thirds from its 2010 baseline. For the countries with the highest maternal mortality burdens like Tanzania, they are required to set a secondary target to have an MMR not greater than 140 deaths per 100,000 live births by 2030.

In Tanzania the MMR from independence in 1961 to the 1990s had been on downward trend (Shija et al., 2011). The population-based surveys of 1999, 2005 and 2010, estimated the maternal mortality ratio to be 528, 578 and 454 per 100,000 live births, respectively (TDHS, 1999, 2005, 2011; TDH-MIS, 2016), (Figure 1). The National Population Census survey of 2012 (URT, 2013), estimated MMR to be 432 per 100,000 live births - being the lowest ever recorded rate since independence. However, the most recent put the mean MMR at 556 per 100,000 (TDH-MIS, 2016), indicating an increase by $28.7 \%$ within three years. During the same period of the past 10 years,

\footnotetext{
${ }^{*}$ Correspondence Email: rumishashoo@gmail.com
} 
WHO/UNICEF/UNFPA/WB estimate of MMR for Tanzania was 950 per 100,000 live births with a range of 620-1,300 per 100,000 live births in the year 2015 (http://data.unicef.org/topic/maternalhealth/maternal-mortality). This gives the total number of maternal deaths in the country to be between 8,000 and 13,000 annually. This decline, and tendency towards rising, is likely to hinder Tanzania reaching the SDG target of 140 maternal deaths per 100,000 by 2030 (MoHSW, 2015). The current level of MMR is also far behind National Strategy for Growth and Reduction of Poverty (NSGRP) target of 265 and MDG target of 133 by 2015 (URT, 2010).

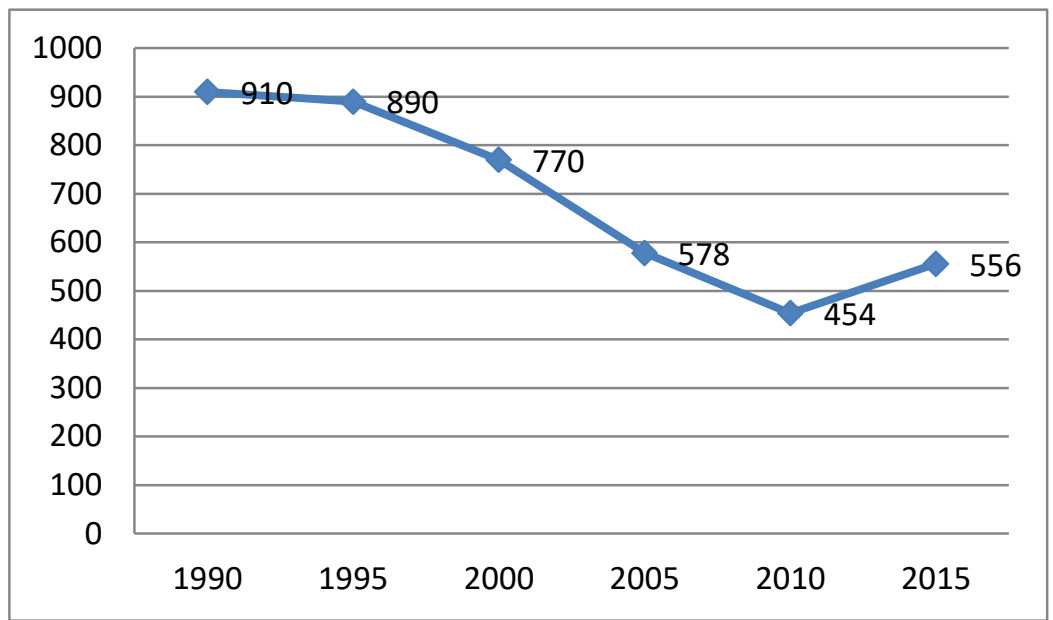

Figure 1: Maternal mortality ratio trends in Tanzania, 1990-2016

This paper presents and analyses the trend of maternal mortality ratio in Tanzania against major events, policy, economic and political decisions which may have influenced this trend. We also look at the impact of other initiatives related to Health Systems Strengthening, contextual issues and we propose alternative strategies for effective maternal mortality reduction in Tanzania.

\section{Materials and Methods}

To identify interventions with significant impact on MMR, we searched Issue 9 (September) 2011 of the Cochrane Database of Systematic Reviews (http://www.cochranelibrary.com/cochranedatabase-of-systematic-reviews/) for all reviews of intrapartum interventions published by the Cochrane Pregnancy and Childbirth Group using the group filter "hm-preg" as our starting point. Systematic reviews of randomised trials of intrapartum interventions were eligible for inclusion. We excluded protocols for systematic reviews and systematic reviews that had been withdrawn. Outcome data were extracted independently from each included review by at least two review authors. Unique lists of salutogenically and non-salutogenically focused outcomes were established. Sixteen salutogenically- and non-salutogenically-focused outcome categories were identified in 102 included reviews. Maternal satisfaction was most frequently reported. Each citation was reviewed independently by at least two members of the team against the inclusion criteria in two stages as follows: title and abstract screening and full text screening of citations judged relevant or potentially relevant for inclusion from stage 1.

On grey literature relevant to Tanzania, we searched the Ministry of Health repository using the key words above for any documents published related to maternal mortality. The paper was later subjected to a critical peer review process for additional data and ideas. As regards to published work, we used the key words identified and searched all published literature on maternal mortality in Tanzania and related health systems factors on-line between 1960 and 2016. 


\section{Monitoring maternal mortality ratio in Tanzania: the trend}

Maternal mortality is difficult to track. Most data on maternal mortality currently in use officially are derived from population surveys as opposed to vital registration which would provide accurate and timely estimates. These figures are expensive to obtain on yearly basis and have wide confidence intervals. As such other more practical measures have to be used to monitor progress. In particular routine facility data collected as part of the Health Management Information System (HMIS) is currently in use in Tanzania to prioritize allocation of resources. This captures the number of deaths due to maternal complications but does not report the number of women admitted due to maternal complications. The Tanzania 2009 HMIS reports identifies regions with the highest number of maternal deaths which included Mwanza (176), Tabora (164) and Dar es Salaam (137); and those with the lowest, Pwani (30), Arusha (32) and Lindi (39) (Ministry of Health, unpubl.). In a recent review of the Tanzania health sector performance the maternal mortality ratio for births within health care facilities during 2011-2012 was 160 deaths per 100,000 live births, with little change noted from the preceding two-year period (Mboera et al., 2015). However, these numbers do not capture deaths outside health care facilities.

\section{What could possibly be related to this MMR trend?}

\section{Political economic and contextual factor}

To answer this question, we examined the political, economic and other contextual factors as well as health system challenges. Economic development, progress on education and emphasis put on training and deploying large numbers of front-line health workers along with expanding rural health facilities made Tanzania stand out as one of the examples for the global learning on Primary Health systems initiatives even before the Alma Ata. The country was achieving more with less investment as compared to countries with the same level of economic development (Newell, 1975). In an analysis of impact using the WHO health systems model (WHO, 2000) and modified using the human rights model (Backman et al., 2008) that covered 42 high mortality countries it was very difficult to predict outcomes because of the existence of a large population of informal sector (McPake et al., 2015). This happens to be the case in Tanzania. This points to the fact that in situations where a large part of the target population consists of the poor, focus of health systems strengthening must address and prioritize issues of equity. The recent population survey report indicates that in Tanzania whereas $95 \%$ of the wealthiest enjoy skilled birth attendance, only $42 \%$ of the poorest get skilled attendance at birth (TDH-MIS, 2016).

\section{Low Investment in health}

Tanzania has steadily invested into Heath Systems Strengthening (HSS). In real terms, the government expenditure in health increased from TShs 1,818 billion (ca. US\$865,714) in 2015/16 to 2,055 billion in 2016/17 fiscal year. Although this is still just 9.5\% (below the required $15 \%$ Abuja target), of the total government budget, there is need to invest these resources wisely to demonstrate a visible impact in order to attract more resources and show value for money. The total cost of Heath Sector Strategic Plan IV 2015-2020 is estimated at TShs 21,945 billion for five years which is about TShs 4,389 billion annually. The deficit between what governments allocates to health compared to actual needs remains huge (West \& Dutta, 2015; Lee et al., 2016). The government therefore needs to invest in those areas which produce the best results with increased demand for accountability and value for money. There are indications this increase of budget is sustainable if the $26 \%$ increase in revenue collection witnessed in 2016 is sustained. This may enlarge the government fiscal space (http://www.tanzaniainvest.com/economy/).

Another positive development has been an increase of development expenditure in the 2016/17 Health Budget which targets longer term investment budget by $39 \%$ while decreasing the recurrent budget by dropping implementation of wasteful activities like unnecessary meetings and 
travels. This is a positive move towards HSS and maternal mortality reduction. A critical analysis into the wasteful nature of government spending however reveals deeper and more serious concerns about lack of accountability, widespread unethical conduct and outright corruption. The health sector is one of the areas that is prone to corruption. In Tanzania, the health sector has been ranked third in the list of sectors with the highest incidence of corruption (http://9iacc.org/papers/day4/ws7/d4ws7_mjmwaffisi.html). Tackling these aspects is challenging as they point to the need of addressing issues of human rights, ethics and accountability as part of HSS to complement the government efforts. In late 2016, the Prime Minister issued a directive that funds should now be sent directly to facilities and thus the need to build capacity among facility and local government staff on management and leadership. Unless planning, budgeting and financial management skills are developed and systems of accountability built, service delivery will not improve. Efforts have concentrated on the supply aspects but little has been done on the demand side.

\section{Low prioritization of maternal and new-born health}

The Tanzania 2015 Countdown analysis shows that maternal and new-born health activities have consistently received less external funding (Afnan-Holmes et al., 2015). In 2010 child health received US\$ 160 million which was almost three times the amount of funding compared to maternal and new-born health. Whereas commendable progress on child mortality reduction has continued (Mboera et al., 2015), multiple linear regression analysis into why this happened reveals that it was as a result of scale up of child survival interventions mainly immunization, the scale up of the use of insecticide treated mosquito nets (ITNs), Vitamin A, introduction of new effective malaria diagnosis and treatment, increased coverage of children reached by integrated management of childhood illnesses and improved governance at district level (Schellenberget al., 2004; Lengeler, 2004). It is our hope that the high impact attained in interventions coverage will be maintained. HSS has to ensure any improvements observed are sustained and institutionalized (De Savigny \& Adam, 2009). Institutionalization of these gains is possible if these vertical interventions deliberately invest in HSS.

There are emerging worrying signals on sustaining this high coverage given the dwindling and unpredictable nature of donor funding for these interventions. Recent statistics have shown that malaria prevalence in Tanzania has risen from 9\% in 2011/12 to 14\% in 2015/16 (TDHS-MIS, 2016). Urgent research needs to be undertaken to explain the rise. It should be pointed out here that the selective high impact interventions approach was part of the Health Reforms agenda adopted in the 1990 s sometimes at the expense of HSS. On a positive note though, it is worth noting here that improved governance at district level was one of the factors that contributed to child survival. This indeed contributes to sustaining HSS.

\section{Poverty and service utilization}

One of the reasons for low utilization of services is poverty. The liberalization policies, the economic reforms and poverty reduction strategies implemented have had very marginal reduction of poverty in Tanzania. The income poverty dropped from 35.7 in 2000/01 to $33.6 \%$ in 2007 and further to $28 \%$ in 2012 (URT, 2012). At the same time, the number of people in poverty actually increased as population grew. When poverty increases in a situation where user charges are also in place, it is not surprising that utilization of health services will drop. User charges introduced in 1994 in referral hospitals were made universal by 2004 covering facilities at all levels. There is established evidence that introduction of even small amounts of user charges tends to exclude the poorest from services and therefore this should be accompanied by effective safety nets to protect the poor (Latreille et al., 2006; Ensor et al., 2008).

Out of pocket expenditure in Tanzania stands at 33\% of the health expenditure. Mechanisms introduced to cover the poor including National Health Insurance Fund (NHIF) targeting those in the formal sector and Community Health Fund targeting the informal sector introduced in 2001 has 
attained coverage of just $23 \%$. A major factor affecting coverage remains the perceived low quality of care in facilities, poor management of funds and lack of trust. Despite existence of free delivery in government facilities, Kruk et al. (2008) found that about three-quarters of rural poor mothers had to pay. Although the total cost was just USD 5.00, most mothers had to sell assets. Direct costs included transport (53.6\%) and payment to providers (27\%) (Kruk et al., 2008). Systems need to be designed not only to address the supply side but to address the client demand issues. We will now examine policy changes and contextual factors that may have influenced this trend using the performance gaps in the formal health care system as the frame of reference.

\section{Formal health system performance gaps}

The most recent demographic and health indicator survey identifies a number of health systems performance gaps at service delivery level which directly impact maternal mortality (Table 1). Out of 13 areas selected, only one area - Antenatal Care (ANC) had what was considered acceptable performance. The most glaring gaps were in contraceptive prevalence, early ANC attendance and postnatal care which scored well below 50\% (TDH-MIS, 2016). These are areas which need to be addressed as a matter of urgency. We will consider four areas: - family planning, optimal quality antenatal care, access to quality emergency obstetric care and postnatal care.

The founder of the Chama cha Uzazi na Malezi Tanzania (The Association for Family Planning) once said: "The approach to population and development should be interdisciplinary. Learn people's priorities and become their partners in development. That approach will promote a peaceful and hopeful future" (Nsekela, 1978). Family planning activities in Tanzania started in 1959 but suffered several setbacks and failed to make an impact despite the well documented health benefits to mothers and children as well as the socio-economic benefits. Family planning has not received sustained political support at the highest level of government. Progress was rapidly achieved after high level intervention in the early 1970 s to late 1980 s when the late President Julius Nyerere himself came out to promote and defended family planning which was under attack from senior government and political party officials. The contraceptive prevalence which was just $7 \%$ in 1999 , now stands at 32\% (TDH-MIS, 2016).

Tanzania today faces a challenge of both population outstripping social services such as education as well as unnecessary maternal deaths due to unwanted pregnancies. Forty-two percent of mothers in Tanzania want to wait for at least two years to have another child and $25 \%$ do not want any more children. Abortion contributes to $16 \%$ of maternal deaths (Woog \& Pembe 2013). Tanzania cannot address the pressing social services issues and maternal deaths by continuing to ignore family planning. Although a National Family planning costed implementation plan was developed in 2010, findings of a recent survey show that most targets are not being achieved (TDH-MIS, 2016).

Antenatal care: Reasons for the decline of ANC visits in Tanzania have been described recently by Gupta et al. (2014). Factors associated with positive association and higher utilization include services provided as a package of services including HIV testing and counselling and intermittent preventive treatment of malaria (using sulfadoxine-pyrimethamine). Low utilization was noted among unmarried mothers, and those living away from health facilities. Of great interest was the finding that provision of family planning services made women to seek earlier booking (Praxton et al., 2006). These findings were used to revise the focused antenatal care guidelines but the impact of the new guidelines has not been assessed.

Intrapartal and postnatal care: Causes of maternal deaths in Tanzania are known and these include direct causes like haemorrhage, eclampsia, sepsis, complications of abortion and obstructed labour. There is almost a universal trend that availability and utilization of Basic Emergency Obstetric care is generally poor compared to comprehensive emergency obstetric care. This means that services available for the poor are of lower quality or simply not available (Praxton et al., 2006). This finding was confirmed by the Tanzania EmNOC national assessment in 2015 
(MoHSW, 2015). In particular, only $25 \%$ of facilities offered the basic 7 of the 9 signal functions (WHO, 2009) while $73 \%$ of the comprehensive emergency new-born and obstetric care (CemNOC) facilities offered caesarean section and blood transfusion. In a study in northern Tanzania, Olsen et al. (2005) concluded that it is not just availability of the service that matters but the quality, efficiency and trust in the services. The critical determinant of utilization was the presence of qualified and trusted staff. Although delivery at government facilities is supposed to be free, anecdotal reports indicate that it is almost universal practice for mothers to be asked to buy their own supplies including gloves, gauze, pads and even water. Studies in Sierra Leone have confirmed that costs also prohibit utilization and mothers are attracted to Traditional Birth Attendants because of their vast experience and compassionate attitude (Oyerinde et al., 2013).

Improving Emergency Obstetric Care is the single most critical action to improve care at birth. The official records by the Ministry of Health show serious deficit in staffing for delivery of Emergency and Basic Emergency Obstetric care. These figures mask the problem of maldistribution and competency which are all important in optimal service delivery. Key staff for delivery of Emergency Obstetric Care are qualified Medical Doctors. Sirili et al. (2014) estimate the deficit of doctors in government and private hospitals to be around $67 \%$ and $87 \%$, respectively. The doctors and nurses/midwives per 10,000 population ratio stands at 0.5 and 4.9 , respectively (Mboera et al., 2015). Moreover, the total health worker density in Tanzania varies from below 4 per 10,000 in Rukwa, Kigoma, Shinyanga and Tabora to more than 10 in Kilimanjaro, Dar es Salaam, and Iringa regions (MoHSW/IHI/NIMR/WHO, 2013). The situation is not improving significantly despite increased effort in production of doctors. Between 2007 and 2012, the study found that only $62 \%$ of graduating medical doctors could be absorbed by government service.

Tanzania will need to formally adopt task shifting which allows Assistant Medical Officers to provide $\mathrm{CEmNOC}$ functions and nurses to provide BEmNOC functions. A review of existing policy and legal frameworks indicates that the Minister of Health and existing Professional Councils have the power to allow this to happen (USAID, 2012). The issue of low coverage of BEmNOC services is partly due to availability of staff but also lack of the requisite skills and supplies. In an obstetric assessment conducted in the high maternal mortality regions in Lake Zone and Western Tanzania, less than $55 \%$ of dispensaries and health centres were able to provide the life-saving BEmNOC services of assisted vaginal delivery, removal of retained products, manual placenta removal or administration of magnesium sulphate for eclampsia (http://data.unicef.org/topic/maternalhealth/maternal-mortality).

Post-natal care: As described earlier, neonatal mortality is closely linked with maternal mortality. A review of unmet needs for neonatal survival in Tanzania has been undertaken by Ndeki et al. (2016). The most serious gaps identified included lack of facilities for diagnosis and prevention of malaria at antenatal care, equipment for resuscitation and keeping the baby warm, low utilization of EmNOC and poor use of the partograph to monitor labour. This indicates that the quality of service delivery is poor. In 2016 the Ministry of Health launched a comprehensive Roadmap for strengthening maternal, new-born and adolescent health. The plan identifies 12 intervention areas along the life cycle and continuum of care (MoHSW, 2015). Implementation of these will ultimately improve new-born care but these interventions need to be prioritized.

Tanzania does not have guidelines that oblige trained health staff to visit mothers in the postnatal period. At the same time this would not be feasible due to shortage of staff for outreach services

\section{Clarity on Health systems strengthening which is client oriented}

Actions in health systems strengthening require a clear and correct conceptualization of HSS. WHO defines health systems as "all the activities whose primary purpose is to promote, restore or maintain health". This is the most widely accepted definition and the one adopted by our approach. The original WHO HSS six blocks model emphasizes interconnection between the blocks but many 
approaches to HSS ignore the interconnectedness and often limit activities to the formal health care system (Ergo et al., 2011). The emphasis on addressing the six blocks is necessary but it should only be an entry point of addressing the demand side. As this inputs (supply) aspect is addressed, the need for monitoring outcomes becomes necessary. The desired outcome is improved health of all people. For the health outcomes to be optimized, equitable, safe and acceptable quality of care must be available to all citizens. This will not be realized unless there is continuous engagement of people using a human rights approach to programming. For all individuals to be reached by services, the system must operate efficiently, responding to changing diseases pattern and designing mechanism which ensure that even the poorest are reached by services. This comprehensive approach is espoused in a model developed by USAID- CHIP (Ergo et al., 2011). The model has three components namely: (i) the health sector - with subcomponents of enabling environment, governance and service delivery; (ii) the community, consisting of physical and social environment; and (iii) the households and individuals.

Going back to the MMR trends in Tanzania, the major events that coincide with the stagnation of MMR trends include the severe economic hardships in the country and the liberalization policies (1985-1995) and the subsequent health sector reform initiatives. A more direct effect on service coverage and quality was the retrenchment of government staff and freeze on employment imposed by implementation of the Breton Woods institutions recommendations and possibly the unregulated private sector. By 2007, Ministry of Health reports indicate that only $32.2 \%$ of vacancies were filled basing what was described as a human resources crisis. There are reports which indicate that even the few staff available lack motivation (Mbilinyi et al., 2011) and often lack the appropriate patient interaction skills.

\section{Addressing the gap using a different approach}

Our experience in Singida region showed that improving management, governanace and leadership can improve health systems functioning. Health sytems strengthning should therefore use leadership governance and management as the entry point to address capabilities that are requisite to addressing MMR (Ndeki et al., 2016). In Singida we found that the supervision system for example concentrated mainly on facility activities without paying attention to consumers. We transformed the supervion from being an inspectorate to being supportive through mentoring and coaching. Health facility staff and managers were taken through a process of identifying their management weaknnesses and were supported to address them instead of always looking for solutions elsewhere. This will hopefully contribute to imprement of maternal health services.

\section{Monitoring outcomes and processesbeyond the numbers}

It is now established that monitoring coverage of emergency obtetric care using the 9 process indicators provides a practical measure of progress on maternal and neonatal mortality reduction. Although process indicators were developed by WHO, UNICEF and UNFPA in 1997, it was not until 2015 when Tanzania conducted its first Nationwide Emergency Obstetric care assessment. Unfotrunately the regular Service Provision Assessments and Service Assessments and Readiness measures do not provide specific enough measures of progress on maternal mortality reduction and do not identify areas needing actions on maternal health. What we must emphasize here is the need to complement these asesssments with qualitative studies of why mothers are not utilizing services and having constant dialogue with communities to address their concerns. The qulitative studies done in Sierra Leone to complement the Emeregency Obteric Care assessment was as useful as the quantitative assessment in guiding maternal health services planning (R. Shoo, unpubl).

Institutionalization of maternal and perinatal deaths review is another useful process that will guide and stimulate actions on maternal deaths and especially involvement of men and entire communities. A review of the maternal and perinatal death programme adopted by Tanzania in 
2006 indicates that the system does not function adequately to either perform good quality review or fulfil the aspiration to capture every facility-based maternal and perinatal death. The concept is not well understood and the emphasis in implementation is often on the reporting of maternal deaths rather that developing solutions on maternal deaths.

\section{Establishing systems of accountability on sexual and reproductive health rights}

We will consider accountability in three areas: - political and democratic accountability, financial accountability and performance accountability. On political accountability tremendous work has been done to advocate for maternal health at highest levels of government. The Ministry of Health needs to capitalize more on this good will. At lower levels emphasis for appropriate use of resources for maternal care must be emphasized. Gender balance in all committees must be ensured. This should include resource mobilization from the private sector including mining, oil and gas companies. The Roadmap is a very useful document for advocating and attracting external funding. The challenge remains how this is carried down to community level. Tracking resources for maternal and new-born activities can be done through the sector-wide approach resource tracking studies. Deliberate effort of transparent resource allocation and utilization can be undertaken to complement current government efforts to fight corruption and misuse of resources. Although the planning process demands community involvement, in reality communities are involved more in implementation and not in setting priorities (Massoi\& Norman, 2009). Communities have to first see maternal death as a concern.

As noted earlier, the health industry is unique in the sense that people influence both performance and outcomes in their role as patients, caretakers, source of financing as well as their individual behaviors in managing health risks. At the same time people run and regulate the industry. Given the people centred nature of the industry, it is heavily dependent of the value it puts on people and the perception people have on its value. Accountability should not only monitor prudent use of resources and outcomes but how those outcomes are achieved. At central level, it is important that adequate resources are allocated to the health sector and are released on time to the areas according to needs. Investing a lot of resources - to build modern well equipped delivery rooms when health workers are rude and charge patients for deliveries will not lead to favourable outcomes on maternal morbidity and mortality. Investing resources in health systems for maternal health should go in tandem in improving staff attitudes. Sirili et al. (2014) point out that that currently the issue is not just shortage of staff but also absorption capacity of those currently being trained. The government could adopt a preferential innovative hiring policy whereby emergency health care providers are hired first. The current staffing norms which do not take into account workload need to be reviewed. Systems of accountability should be built up using human rights principles at central, regional, district, facility and community levels.

Performance accountability through Maternal and Perinatal Death Reviews (MPDR) was established since 2006 with development of national guidelines. As mentioned earlier among areas that HSS must invest in is a systematic support of Maternal and Neonatal Death Reviews at all levels and mechanism of supporting dialogue and actions to address issues identified. Although MPDR has been institutionalized since 2006, the quality, understanding of the value and action has been found to be insufficient (Armstrong et al., 2014). A deeper capability analysis needs to be undertaken in order to support and launch this process with a new impetus. This process will help focus maternal mortality reduction activities towards problems identified at district level.

\section{Deliberate efforts to reach the unreached - need for context specific solutions}

Reaching the unreached communities especially the poor, nomadic and other isolated communities require strategies tailored to the actual situation. Current business as usual approaches are unlikely to address issues facing these groups. Further gains in health improvement must target these communities. Failure to take these deliberate measures will result into increasing inequalities. 
Table 1. Maternal and new-born heath care health system performance gaps Tanzania 2016

\begin{tabular}{|c|c|c|c|}
\hline & Area of action & & Programmatic action \\
\hline & Teenage pregnancy & $27 \%$ & Life skills education nationwide with Ministry of Education \\
\hline \multirow[t]{3}{*}{ Antenatal } & First ANC visit in first trimester & $24 \%$ & National Advocacy action with reward to winning Region \\
\hline & Four recommended ANC visits & $51 \%$ & National advocacy with award to winning region \\
\hline & ANC by skilled attendant & $98 \%$ & Work on quality \\
\hline \multirow[t]{2}{*}{ Intrapartal } & Institutional deliveries & $63 \%$ & $\begin{array}{l}\text { Quality improvement with district scorecards shared } \\
\text { publicly }\end{array}$ \\
\hline & Delivery by Skilled attendant & $64 \%$ & $\begin{array}{l}\text { Support e-learning midwives program - by training } \\
\text { institutions } \\
\text { Introduce a mandatory Ethics module for in-service and pre- } \\
\text { service by training institutions and Continuing Education } \\
\text { Ministry of Health to develop policy and regulatory } \\
\text { framework on Task shifting to allow BEmNOC for nurses } \\
\text { and CEmNOC for Assistant Medical Officers }\end{array}$ \\
\hline \multirow[t]{7}{*}{ Post-partal } & $\begin{array}{l}\text { Post-natal care within } 2 \text { days } \\
\text { for mother }\end{array}$ & $44 \%$ & $\begin{array}{l}\text { Develop a Home Visitors Programme among trained } \\
\text { Community Health Workers (CHW) }\end{array}$ \\
\hline & $\begin{array}{l}\text { Postnatal care within } 2 \text { days } \\
\text { for baby }\end{array}$ & $32 \%$ & $\begin{array}{l}\text { Train CHW - health visitors on essential home based } \\
\text { newborn care }\end{array}$ \\
\hline & $\begin{array}{l}\text { Women wanting to wait for at } \\
\text { least two years before another } \\
\text { baby }\end{array}$ & $42 \%$ & $\begin{array}{l}\text { National support for family planning in all political parties' } \\
\text { manifestos } \\
\text { Solicit Media and private sector support }\end{array}$ \\
\hline & $\begin{array}{l}\text { Women who do not want any } \\
\text { more children }\end{array}$ & $26 \%$ & $\begin{array}{l}\mathrm{RCH} \text { to lead a media and public information campaign } \\
\text { Religious and community leaders' sensitization by } \mathrm{RCH}\end{array}$ \\
\hline & Contraceptive prevalence rate & $32 \%$ & $\begin{array}{l}\text { Countrywide National Information Education and } \\
\text { Communication campaign targeting opinion leaders, men } \\
\text { women }\end{array}$ \\
\hline & Equity & & $\begin{array}{l}\text { Increase insurance cover for pregnant women to } 80 \% \text {. } \\
\text { Establish an independent national equity monitoring and } \\
\text { reporting programme }\end{array}$ \\
\hline & Quality improvement & & $\begin{array}{l}\text { Nationwide scale up of the quality assurance programme } \\
\text { focusing on maternal and newborn care } \\
\text { Reinforce mandatory maternal and perinatal death reviews } \\
\text { in all facilities } \\
\text { Introduce nation-wide community maternal and perinatal } \\
\text { death review }\end{array}$ \\
\hline \multicolumn{2}{|c|}{ Key: Acceptable } & & \\
\hline \multicolumn{2}{|c|}{ Unacceptable } & & \\
\hline
\end{tabular}

For resource allocation purposes, districts may have to be grouped by maternal mortality levels and other criteria based on existing inequalities. Studies undertaken in these communities show that the problems of health services utilization are complex. In Ngorongoro Conservation Area for example where MMR is currently 642/100,000 among the nomadic Maasai, mothers seeking skilled care at birth is only $7 \%$. Using the Thaddeus \& Maine (1994) three delay model, Roggeveen et al. (2013) identified a number of complex issues including: negative perception on quality of service, fear on discontinuity of care by TBA, food and financial security, desired nearness to cattle and family, males not aware of dangers of child birth, giving birth in facilities seen as lack of courage, no birth preparedness and limited human resources. The TBA in particular is believed to have a spiritual link with Engai (the Maasai God) and therefore there is fear in discontinuation with this link by delivering at facilities. Context specific solutions must therefore be developed for these situations. This calls for an approach to Maternal and Newborn health programming which emphasizes learning by doing and finding solutions that are appropriate to the local situation rather than implementing programmes using templates provided. 


\section{The way forward}

Based on our analysis and the urgency of this problem we propose the actions as summarized in Table 1 based on the gaps identified. These actions require largely optimization of existing structures and rational use of existing resources. What is required is the will and commitment.

A review of the MDGs progress indicates that Tanzania registered commendable progress in child mortality but not in maternal and neonatal mortality (Afnan-Holmes et al., 2015; Mboera et al., 2015). Whereas child mortality reduction largely depends on high coverage of cost effective interventions, maternal and neonatal mortality depends on Health Systems Strengthening (HSS). Any further gains on maternal mortality reduction in Tanzania will depend on robust health systems strengthening accompanied by effective application of a human rights approach to maternal health programming. In order to address the problem of MMR, it is crucial that actions are based on an analysis of capabilities based on the competencies, resources, assets and authority to perform tasks that effectively contribute to maternal mortality reduction at all points of service delivery. Most policies and strategies on MMR have been designed without a thorough analysis of clarity of roles in the devolved and decentralized system where health facilities are effectives under the stewardship of the President's Office Regional Administration and Local Government. A capability analysis by PMO-RALG - Health reveals revels lack of the notion of getting the most of available resources by capitalizing working effectively and efficiently (DANIDA, 2016). At service delivery level, health staff lack creativity and tend to address problems at facility level without root cause analysis of problems. We propose that any actions on maternal mortality reduction that are adopted take into account the new disposition and build a culture programming based on root cause analysis especially at service delivery points based on local realities. This approach is both effective and sustainable.

In conclusion, our review of progress in maternal mortality in Tanzania indicates that the problem is growing worse because lower coverage of interventions and inadequacy of governance and leadership in the delivery of the services such as lack of supportive supervision and inadequate funding. We argue that there is need for a paradigm change in addressing this problem. Interventions have increasingly left out the poor and rural isolated communities. We call for a rights- based approach where maternal deaths interventions are planned and implemented after a root cause analysis at community and facility levels. We are optimistic that with this change of approach among all stakeholders, progress will be realized along the Sustainable Development Goals.

\section{Competing interests}

The authors declare that they have no competing interest.

\section{References}

Afnan-Holmes, H., Magoma, M., John, T., Levira, F., Msemo, G., Armstrong, C.E., Martínez-Álvarez, M., Kerber, K., Kihinga, C., Makuwani, A., Rusibamayila, N., Hussein,A., Lawn, J.E. (2015) Tanzania's Countdown to 2015: an analysis of two decades of progress and gaps for reproductive, maternal, newborn, and child health, to inform priorities for post-2015. Lancet Global Health 3 97): e396-e409.

Alkema, L., Chou, D., Hogan, D., Zhang, S., Moller, A.B., Fat, D.M., Boerma, J., Timmerman, M., Maters, C., Say, L. (2016) Global, regional, and national trends in maternal mortality between 1990-2015 with scenario based projections to 2013: a systematic analysis by the UN Maternal Mortality Estimation Interagency Group. Lancet 387: 462-474.

Armstrong, C.E., Lange, L., Magoma, M., Ferla, C., Fillipi, V. \& Ronsmans, C. (2014) Strengths and weaknesses in the implementation of maternal and perinatal death reviews in Tanzania: 
perceptions, processes and practice. Tropical Medicine and International Health 19: 10871095.

Backman, G., Hunt, P., Khosla, R., Jaramillo-Strouss, C., Fikre, B.M., Rumble, C., Pevalin, D., Paez, D.A., Pineda, M.A., Friesancho, A., Tarco, D., Motlagh, M., Farcasanu, D. \& Vladescu, C. (2008) Health systems and the right to health: an assessment of 194 countries. Lancet 372: 2047-2048.

DANIDA (2016) Analysis of capability of PMO-RALG: Health to ensure the implementation of the Health Sector Support Programme IV. DANIDA, 2016.

De Savigny, D. \& Adam, J. (2009) Systems Thinking for Health Systems Strengthening. World Health Organization, Geneva, Switzerland.

Ensor, T., Lievens, T. \& Naylor, M. (2008) Review of Health Financing in Sierra Leone and Development of Policy Options. Oxford Policy development.

Ergo, A., Eichler, R., Koblinsky, M. \& Shah, N. (2011) Strengthening Health Systems to Improve Maternal, Neonatal and Child Health Outcomes: A Framework. USAID. http://www.mchip.net/sites/default/files/

GBD (2016) GBD 2015 Maternal Mortality Collaborators. Global, regional, and national levels of maternal mortality, 1990-2015: a systematic analysis for the Global Burden of Disease Study 2015. Lancet 388: 1775-1812.

Gupta, S., Yamada, G., Mpembeni, R., Frumence, G., Callaghan-Koru, J.A., Stevenson, R., Brandes, N. \& Baqui, A.H. (2014) Factors associated with four or more antenatal care visits and its decline among pregnant women in Tanzania between 1999 and 2010. PLoS One 9(7): e101893.

Kruk, M.E., Mbaruku, G., Rokers, P. \& Galea, S. (2008) User fee exemptions are not enough: out of pocket payment for "free" delivery services in rural Tanzania. Tropical Medicine and International Health 13: 1442-1451.

Latreille, K., Coppens, K., Phillips, M., van Herp, M., Bachy, C. \& Ponsar, F. (2006) Financial Access to Healthcare in Postwar Sierra Leone. Freetown: Medicins Sans Frontiers Holland and Belgium.

Lee, B. \& Dutta, A., Lyimo, H. (2016) Analysis of the Government of Tanzania Ministry of Health, Community Development, Gender, Elderly and Children Budget Fiscal Year 2016/17. USAID, PEPFAR HP4.

Lengeler, C. (2004) Insecticide treated bed nets and curtains for preventing malaria. Cochrane Review. Cochrane Database for Systematic Reviews 2000.

Massoi, L. \& Norman, A.S (2009) Decentralization by devolution in Tanzania: reflections on community involvement in the planning process in Kizito Ward in Dodoma. Journal of Public Administration and Policy Research 1: 137-140.

Mbilinyi, D., Daniel, M. L. \& Lie, G. T. (2011) Health worker motivation in the context of HIV care and treatment challenges in Mbeya Region, Tanzania: a qualitative study. BMC Health Services Research 11: 266.

Mboera, L.E.G., Ipuge, Y., Kumalija, J. Rubona, C.J., Perera, S., Masanja, H. \& Boerma, T. (2015) Midterm review of national health plans: an example from the United Republic of Tanzania. Bulletin of the World Health Organization 93: 271-278.

McPake, B., Edoka, I., Witter, S., Kielmann, K., Taegtmeyer, M., Dieleman, M., Vaughan, K., Gama, E., Kok, M., Datiko, D., Otiso, L., Ahmed, R., Squires, N., Suraratdecha, C. \& Cometto, G. (2015) Cost-effectiveness of community-based practitioner programmes in Ethiopia, Indonesia and Kenya. Bulletin of the World Health Organization 93: 631-639.

MoHSW (2015) Nationwide Assessment of Emergency Obstetric Care 2015. Ministry of Health and Social Welfare, Dar es Salaam, Tanzania

MoHSW/IHI/NIMR/WHO (2013) Mid-term Analytical Review of Performance of the Health Sector Strategic Plan III 2009-2015. Ministry of Health and Social Welfare, Ifakara Health Institute, National Institute for Medical Research and World Health Organization. 
Ndeki, S.S., Romore, I. \& Manzi, F. (2016) Addressing Unmet Need for Neonatal Survival in Tanzania: A Synthesis Report. http://int.search.tb.ask.com/search/

Newell, K. (1975) Health by the people. World Health Organization, Geneva.

Nsekela, C. (1978) Family Planning in Tanzania (UMATI). Tanzania Affairs Newsletter.

Olsen, O.E., Ndeki, S., Norheim, O.F. (2005) Availability, distribution and use of emergency obstetric care in northern Tanzania. Health Policy \& Planning 20: 167-175

Oyerinde, K., Harding, Y., Amara, P., Garbrah-Aidoo, N., Kanu, R., Oulare, M., Shoo, R. \& Daoh, K. (2013) A qualitative evaluation of the choice of traditional birth attendants for maternity care in 2008 Sierra Leone: implications for universal skilled attendance at delivery. Maternal and Child Health Journal 17: 862-868.

Praxton, A., Bailey, P., Lobis, S. \& Fry, D. (2006) Global availability of emergency obstetric care. International Journal of Gynecology and Obstetrics 93: 3000-3007.

Roggeveen, Y., Birks, L., van Kats, J., Manyama, Mange, Hatfield, J., Bunders, J., Scheele \& van Roosmalen, J. (2013) Low utilization of skilled birth attendants in Ngorongoro Conservation Area, Tanzania: A complex reality requiring action. Health 5: 71-83

Schellenberg, J.R.M., Adam, T., Mshinda, H., Masanja, H., Kabadi, G., Mukasa, O., John, T., Charles, S., Nathan, R., Wilczynska, K., Mgalula, L., Mbuya, C., Mswia, R., Manzi, F., de Savigny, D., Schellenberg, D., Victora, C. (2004) Effectiveness and cost of facility-based integrated management of childhood illnesses in Tanzania. Lancet 362: 1583-1584.

Shija, A., Msovela, J., Mboera, L.E.G. (2011) Maternal mortality in fifty years of Tanzania independecy: challenges and opportunities of reducing maternal mortality. Tanzania Journal of Health Research 13: 352-364

Sirili, N., Kiwara, A., Nyongole, O., Frumence, G., Semakafu, A. \& Hurtig, A.K. (2014) Addressing the human resource for health crisis in Tanzania: the lost in transition syndrome. Tanzania Journal of Health Research 16: 104-111.

TDH-MIS (2016) Tanzania Demographic and Health Survey and Malaria Indicator Survey. Ministry of Helath, Community Development, Gender, Elderly and Children (Tanzania Mainland), Ministry of Health (Zanzibar), National Bureau of Statistics, Office of the Chief Government Statistician, and ICF. Dar es Salaam, Tanzania and Rockville, Maryland, USA.

TDHS (1999) Tanzania Demographic and Health Survey. National Bureau of Statistics and ORC Macro, Calverton, Maryland, USA.

TDHS (2005) Tanzania Demographic and Health Survey 2004-05. National Bureau of Statistics and ORC Macro, Calverton, Maryland, USA.

TDHS (2011) Tanzania Demographic and Health Survey 2010-11. National Bureau of Statistics and ICF Macro. Calverton, Maryland, USA.

Thaddeus, S. \& Maine, D. (1994) Too far to walk: Maternal mortality in context. Social Science \& Medicine 38: 1091-1110.

URT (2010) National Strategy for Growth and Reduction of Poverty II. Ministry of Finance and Economic Affairs, United Republic of Tanzania.

URT (2012) Tanzania Household Budget Survey 2011-2012. Sixth Round. National Bureau of Statistics, United Republic of Tanzania

URT (2013) Population and Housing Census 2012. United Republic of Tanzania, Dar es Salaam, 2013. USAID (2012) Analysis of Policy Legal and Regulatory Frameworks for Task Shifting in Tanzania. USAID Health Policy Initiatives 2012.

West, K. \& Dutta, A. (2015) Prospects for sustainable health financing in Tanzania. Policy Brief Health Financing Working Group. Ministry of Health, United Republic of Tanzania

WHO (2000) Health Systems Strengthening. World Health Organization, Geneva.

Woog, V. \& Pembe, A.B. (2013) Unsafe abortion in Tanzania: a review of the evidence. Guthmacher Institute, 2013, New York. http://www.guttmacher.org/pubs/ 